\title{
Fat-Mobilizing Action of Amphetamine
}

\author{
E. J. Pinter and C. J. Pattee \\ From the Clinical Investigation Unit, Queen Mary Veterans Hospital, and the \\ Department of Investigatice Medicine, McGill University, \\ Montreal, Canada
}

A B S TRACT The effects of amphetamine and methamphetamine on plasma free fatty acid (FFA), blood glucose, serum total fat, and triglyceride concentrations were investigated in 21 subjects; the effect of epinephrine were studied in an identical manner in 14 subjects.

The administration of amphetamine and methamphetamine led to an increase in the plasma FFA concentration. No significant changes were found in the blood glucose, serum total fat, and triglyceride concentrations.

Kinetic studies of FFA were also made in some of the subjects receiving amphetamine, methamphetamine, and epinephrine. It was shown that amphetamine and methamphetamine lead to an augmentation of plasma FFA pool due to a primary increase of FFA production rate.

Catecholamine depletion, by prolonged parenteral administration of reserpine, nearly completely abolished the adipokinetic action of amphetamine whereas the effect of epinephrine was greatly potentiated. This was interpreted as evidence for the dependence of the adipokinetic action of amphetamine on endogenous catecholamines.

Estimated from a dose ratio (amphetamine: epinephrine) of $352: 1$, the relative adipokinetic potency of amphetamine, expressed as peak $\triangle F F A$ rise, $+\triangle \mathrm{FFA}$ area, and $\triangle \mathrm{FFA}$ production rate, respectively, was found to be 55,84 , and $39 \%$ in comparison with the same effects of epinephrine. The more pronounced changes in $+\triangle \mathrm{FFA}$ area

\footnotetext{
A preliminary form of this study was presented to the Canadian Society for Clinical Investigation, Meeting 1965, Toronto. 1965 J. Clin. Invest. 44 : 1086. (Abstr.)

Received for publication 27 March 1967 and in revised form 23 October 1967.
}

reflect the longer duration of action of amphetamine viz. epinephrine.

This study demonstrates that amphetamine is an adipokinetic agent causing an increase in the plasma FFA pool of a lesser extent but of longer duration than equipressor doses of epinephrine. The mechanism of fat-mobilizing action of amphetamine is indirect i.e., dependent on endogenous catecholamine release.

\section{INTRODUCTION}

The mammalian endocrine system produces two groups of adipokinetic substances, defined as causing free fatty acid (FFA) release according to the first order of kinetics from adipose tissue in vitro: the fat-mobilizing polypeptide hormones of pituitary (1) and of pancreatic origin (2) and the catecholamines (3). Numerous synthetic analogues of the naturally occurring sympathomimetic amines were shown to have varying capacities for mobilizing fat (4). No information is available, however, on the adipokinetic action of amphetamine.

The cardiovascular effects of amphetamine have been extensively studied $(5,6)$. The mode of action, with the exception of central nervous system effects, was stated to be indirect, i.e., it has been suggested that amphetamine acts by releasing endogenous catecholamines or through an effect on serotonin receptors $(7,8)$.

In this study evidence was obtained that amphetamine causes an increase in plasma FFA levels. The amphetamine induced rise in the concentration of circulating FFA was found to be different in both magnitude and temporal sequence from that obtained after intravenous epinephrine. The 
assumption that increments in plasma FFA levels after amphetamine administration were due to increased FFA production was corroborated with successive injections of ${ }^{14} \mathrm{C}$-labeled, albumin-bound palmitic acid. It was also shown, based on studies with catecholamine depletion, that the adipokinetic effect of amphetamine was predominantly dependent on the presence of endogenous catecholamines.

\section{METHODS}

A group of 44 volunteers of both sexes (24 lean and 20 obese) were studied. The obese subjects were kept on a moderately restricted diet whereas the food intake of the lean subjects was not controlled.

All procedures were conducted within an 8-14 hr postabsorptive period at complete physical rest, in a darkened room. Venous blood was obtained without obstruction of blood flow through an indwelling needle kept patent by $0.9 \%$ saline infused at a rate of approximately $60 \mathrm{ml} / \mathrm{hr}$.

In order to measure the adipokinetic action of the different substances used, we adopted the following standardized procedure : venous blood was collected at intervals of $20 \mathrm{~min}$, in the resting state on three occasions (usually between 8 a.m. and 9 a.m.) into heparinized tubes, and kept on crushed ice. The adipokinetic compound, dissolved in $50 \mathrm{ml}$ of $0.9 \%$ saline, was then infused into the antecubital vein at a steady rate during a period of $15 \mathrm{~min}$. Blood samples were obtained at the 10 th $\mathrm{min}$ of infusion and at $0.10,20,30,45,60$, and $90 \mathrm{~min}$ after the infusion.

Other agents which were expected to modify the adipokinetic action of epinephrine or amphetamine (with the exception of reserpine-see below) were administered as intravenous saline infusions preceding the adipokinetic agent. There was some variation in the time intervals between infusions, depending on the compound used for pretreatment. but the basic protocols for amphetamine or epinephrine were identical.

A detailed description of the various procedures used is given below, under Results, grouped according to the aims of this study.

In the kinetic studies rapid intravenous injections of albumin-bound palmitic acid-1" $\mathrm{C}$ were given before and after the infusion of the adipokinetic agents. Five or six blood samples were obtained at 2-min intervals after each injection of the tracer.

\section{Compounds}

Adipokinetic. (a) Epinephrine hydrochloride (Parke Davis, Detroit, Mich.) total dose, $0.500 \mu \mathrm{g} / \mathrm{kg}$ i.v. for 15 $\min (0.416 \mu \mathrm{g} / \mathrm{kg}$ epinephrine base). (b) Amphetamine sulfate (Benzedrine, Smith, Kline \& French Laboratories, Philadelphia, $\mathrm{Pa}$.), total dose, $0.200 \mathrm{mg} / \mathrm{kg}$ i.v. for $15 \mathrm{~min}(0.146 \mathrm{mg} / \mathrm{kg}$ amphetamine base). (c) ITethamphetamine hydrochloride (Methedrine, Burroughs IVellcome \& Co. Tuckahoe, N. Y.) ; total dose, $0.200 \mathrm{mg}$ / $\mathrm{kg}$ i. v. for $15 \mathrm{~min}(0.160 \mathrm{mg} / \mathrm{kg}$ methamphetamine base $)$.
Adrenergic inhibitors. (a) Dihydroergotamine methanesulfonate (DHE 45, Sandoz, Inc., New York, N. Y.) ; total dose, $2 \mathrm{mg}$ i.v. for $30 \mathrm{~min}$ preceding the adipokinetic infusion by $60 \mathrm{~min}$. (b) Reserpine (Ciba Pharmaceutical Company, Summit, N. J.) ; a 48 hr pretreatment period with 8 hourly i.m. injections of $5 \mathrm{mg}$ reserpine followed by the usual adipokinetic procedures.

Tracer. Albumin-bound palmitic acid-1- ${ }^{14} \mathrm{C}$ (New England Nuclear Corp., Boston, Mass.). Each tracer injection contained 2 or $5 \mu \mathrm{c}$ of ${ }^{14} \mathrm{C}$ in $6-10 \mathrm{ml}$ of $25 \%$ salt-poor human serum albumin. The tracer was prepared by exposing unsaponified palmitic acid- ${ }^{14} \mathrm{C}$ to albumin solution on a sterile surface, a procedure based on the principles of a method described previously $(9,10)$.

\section{Methods for kinetic studies}

The isotope studies were based on the method of successive measured injection of tracer substance $(11,12)$. The actual procedure employed was a technical modification of the method described by Wrenshall and Hetenyi for the study of rates of transfer and pool sizes of glucose (13). Radioactivity was measured in a liquid scintillation spectrometer (Ansitron).

The calculations of the rate of transfer of FFA and of the FFA pool size were based on the quantity dilution principle. An IBM 7094 digital computer was programmed to carry out all calculations in the kinetic studies.

Total fat was determined by a gravimetric method (14), triglyceride according to the method of Van Handel and Zilversmit (15), FFA by the Dole procedure $(16), 1$ and blood sugar in an AutoAnalyzer with the method of Hoffman (18). FFA were prepared for isotope counting by a saponification extraction (19). This involved an initial extraction, as in the Dole procedure, followed by the addition of $0.1 \mathrm{~N} \mathrm{NaOH}$ in order to convert the fatty acids to the sodium salt and to extract them into an aqueous phase. Finally, after acidification, the fatty acids were reextracted with heptane. The above procedure eliminated all other lipid elements in the final extract which was used for FFA titration and isotone counting.

\section{RESULTS}

\section{Adipokinetic action of amphetamine (Fig. 1)}

15 patients were studied. In all, the FFA levels rose and reached a peak $30 \mathrm{~min}$ after amphetamine infusion. The average rise, expressed as $\triangle F F A$

\footnotetext{
1 We previously determined FFA using simultaneously the Dole procedure and the Trout modification (17) before, during, and after different agents that influence fat mobilization (epinephrine, nicotinic acid, and propranolol) on 10 occasions. As expected, the FFA concentrations obtained by the unmodified Dole method were consistently higher $(6-18 \%)$. We found, however, that the changes vs. the resting values of FFA ( $\triangle F F A$ ) were reflected within $a \pm 12 \%$ range of error by the Dole procedure.
}

Fat-Mobilizing Action of Amphetamine 


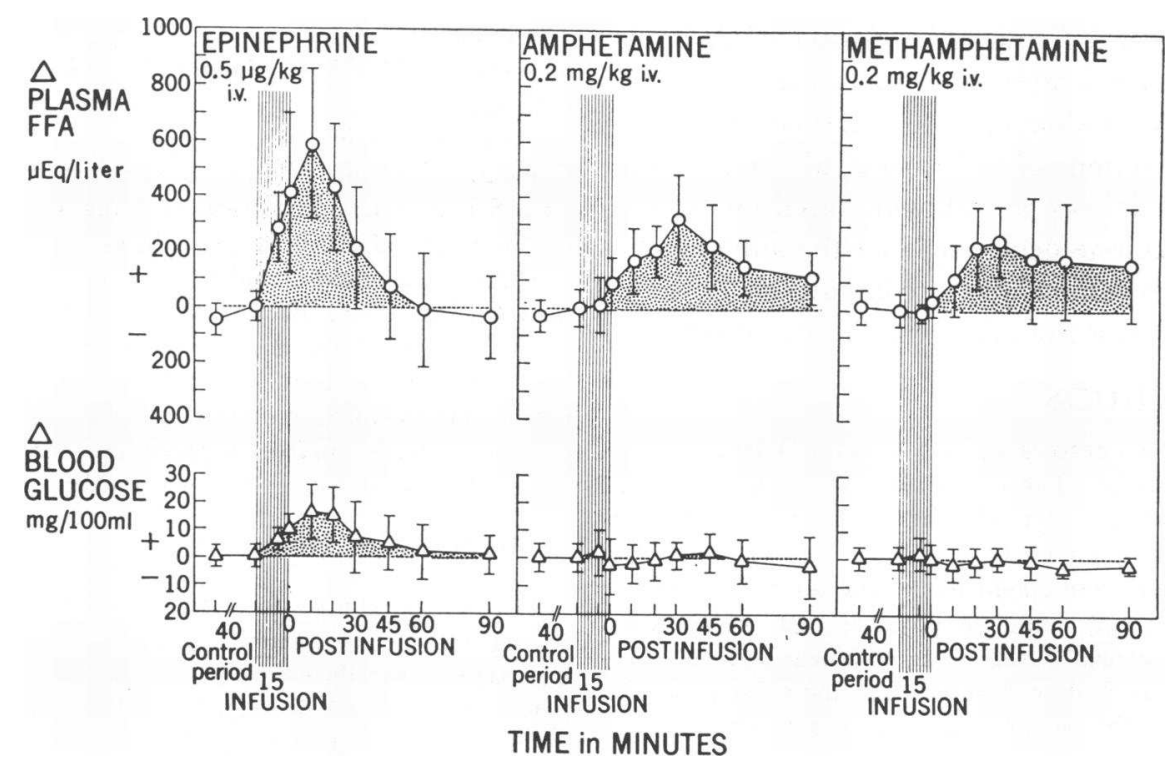

FIGURE 1 The effect of intravenous epinephrine, amphetamine, and methamphetamine infusions on plasma FFA and blood glucose levels (in 14, 15, and 6 subjects respectively). The individual curves show the mean changes $(\Delta) \pm$ SD in relation to the base line levels obtained in the control periods. The shaded areas represent the $+\Delta \mathrm{FFA}$ and $+\Delta$ blood glucose areas; bounded by the temporal plot of $\Delta \mathrm{FFA}$ and $\Delta$ blood glucose from the beginning of the infusions up to $90 \mathrm{~min}$ and by a horizontal line drawn at the level of hase line concentrations.

in relation to the FFA value obtained at the end of a $40 \mathrm{~min}$ period of rest in bed, was $326 \pm 163 \mu \mathrm{Eq} /$ liter above the preinfusion concentration. ${ }^{2}$ Plasma FFA levels were still above the resting range at $90 \mathrm{~min}$ after the infusion of the compound.

In order to compare the blood FFA rise after injecting amphetamine with that after epinephrine, we infused epinephrine in 14 subjects ( 9 of these were also included in the amphetamine series). The mean peak FFA concentration amounting to $589 \pm 265 \mu \mathrm{Eq} /$ liter of FFA above the preinfusion level occurred $10 \mathrm{~min}$ after epinephrine administration. Epinephrine produced an increase in blood sugar in contrast to amphetamine.

The mean slopes ${ }^{3}$ of rising FFA concentrations

2 The absolute variation of the plasma FFA concentrations from the beginning to the end of the control period was $+11 \pm 63 \mu \mathrm{Eq} /$ liter. In 40 randomly selected patients under identical conditions of bed rest and saline administration the following mean plasma FFA values were obtained : $0 \mathrm{~min} 774 \pm 261 \mu \mathrm{Eq} /$ liter ; $20 \mathrm{~min}, 810 \pm$ $281 \mu \mathrm{Eq} /$ liter ; $40 \mathrm{~min}, 776 \pm 227 \mu \mathrm{Eq} /$ liter.

3 The slope is expressed as the tangent of the angle of inclination/unit of time of the mean FFA curve, $(\tan \alpha=$ $\Delta y / \Delta x=\Delta \mathrm{FFA} / \Delta t)$. for amphetamine and epinephrine were found to be +7.17 and +23.55 , respectively. A similar difference was found in the early returning slopes (amphetamine, - 5.70; epinephrine, - 15.35).

The basal concentrations of total fat and triglyceride were $568 \pm 181,587 \pm 82$ and $92 \pm 21$, $96 \pm 34 \mathrm{mg} / 100 \mathrm{ml}$ in the amphetamine and epinephrine groups, respectively. These showed no significant changes up to 90 min after the administration of amphetamine and epinephrine.

2. Measurement of amphetamine induced adipokinesis with ${ }^{14} \mathrm{C}$-labeled, albumin-bound palmitic acid (Tables I and II)

In four individuals (obese and lean) rapid intravenous injections of albumin-bound palmitate${ }^{14} \mathrm{C}$ were made before and at $12 \mathrm{~min}$ after amphetamine infusion. Both the rate of appearance of FFA, and FFA pool size increased. The increment in FFA pool size was due to increased fat mobilization since the rate of disappearance of FFA showed no simultaneous decrease. Actually an increment was seen in the FFA disappearance rates, presumably due to a mass action effect of the increased 
TABLE I

Kinetic Data of Plasma FFA at Rest (Control Period) and after a 15 Min Intravenous Infusion of Amphetamine $(0.2 \mathrm{mg} / \mathrm{kg})$

\begin{tabular}{|c|c|c|c|c|c|c|c|c|}
\hline \multirow[b]{2}{*}{ Subjects } & \multicolumn{4}{|c|}{ Control period } & \multicolumn{4}{|c|}{$\begin{array}{l}12 \text { Min post i.v. } \\
\text { amphetamine }\end{array}$} \\
\hline & $\mathrm{N}$ & $\mathbf{R a}$ & $\mathbf{R d}$ & $\lambda$ & $\mathbf{N}$ & $\mathbf{R a}$ & $\mathbf{R d}$ & $\lambda$ \\
\hline 1 & 4330 & 1000 & 1035 & 0.231 & 6960 & 1488 & 1463 & 0.213 \\
\hline 2 & 3900 & 945 & 985 & 0.242 & 5425 & 1234 & 1150 & 0.227 \\
\hline 3 & 4000 & 870 & 895 & 0.217 & 5600 & 1495 & 1362 & 0.267 \\
\hline 4 & 2210 & 663 & 665 & 0.300 & 3390 & 745 & 774 & 0.220 \\
\hline \multirow[t]{2}{*}{ Mean } & 3730 & 870 & 895 & 0.248 & 5405 & 1240 & 1187 & 0.232 \\
\hline & & & & & \multicolumn{4}{|c|}{$\begin{array}{l}\text { Post i.v. } \\
\text { methamphetamine }\end{array}$} \\
\hline $5^{*}$ & 4210 & 1032 & 1040 & 0.246 & 5650 & 1372 & 1395 & 0.243 \\
\hline
\end{tabular}

N : plasma FFA pool $(\mu \mathrm{Eq}) ; \mathrm{Ra}$ : plasma FFA production (rate of appearance, $\mu \mathrm{Eq} / \mathrm{min}$ ) ; Rd: plasma FFA utilization (rate of disappearance, $\mu \mathrm{Eq} / \mathrm{min}) ; \lambda$ : fractional turnover rate, $0.693147 / \iota_{3}$.

* One subject, given a $15 \mathrm{~min}$ intravenous inf usion of methampheta$\operatorname{mine}(0.2 \mathrm{mg} / \mathrm{kg})$.

amount of circulating FFA. Methamphetamine was also followed by an increase in the rate of FFA production and of FFA pool (one patient).

In order to compare the magnitude of these changes with those after epinephrine, we gave tracer injections before and at $0 \mathrm{~min}$ after epinephrine infusion in five patients (obese and lean). The increments in FFA pool again were due to a primary rise of FFA appearance rates.
TABLE II

Kinetic Data of Plasma FF.t at Rest (Control Period) and after a $15 \mathrm{Min}$ Intraienous Infusion of Epinephrine $(0.5 \mu \mathrm{g} / \mathrm{kg})$

\begin{tabular}{|c|c|c|c|c|c|c|c|c|}
\hline \multirow[b]{2}{*}{ Subjects } & \multicolumn{4}{|c|}{ Control period } & \multicolumn{4}{|c|}{$\begin{array}{l}\text { Min post i.v. } \\
\text { epinephrine }\end{array}$} \\
\hline & $\mathbf{N}$ & $\mathbf{R a}$ & $\mathbf{R d}$ & $\lambda$ & $\mathbf{N}$ & $\mathbf{R a}$ & $\mathbf{R d}$ & $\boldsymbol{\lambda}$ \\
\hline 1 & 4050 & 915 & 1040 & 0.226 & 10170 & 2280 & 1842 & 0.224 \\
\hline 2 & 3420 & 1028 & 955 & 0.300 & 7600 & 2210 & 1780 & 0.290 \\
\hline 3 & 2485 & 910 & 910 & 0.365 & 10710 & 1700 & 1670 & 0.158 \\
\hline 4 & 6450 & 1825 & 1620 & 0.283 & 12610 & 2430 & 2185 & 0.193 \\
\hline 5 & 4570 & 1038 & 923 & 0.227 & 9260 & 1865 & 1680 & 0.201 \\
\hline Mean & 4400 & 1142 & 1090 & 0.280 & 10060 & 2100 & 1832 & 0.215 \\
\hline
\end{tabular}

N : plasma FFA pool $(\mu \mathrm{Eq}) ; \mathrm{Ra}$ : plasma FFA production (rate of appearance, $\mu \mathrm{Eq} / \mathrm{min}$ ); Rd : plasma FFA utilization (rate of disappearance, $\mu \mathrm{Eq} / \mathrm{min}) ; \lambda$ : fractional turnover rate $0.693147 / t_{2}^{\prime}$.

3. Adipokinetic action of methamphetamine (Fig. 1, Table I)

In the six patients studied there was an average rise of FFA levels of $244 \pm 125 \mu \mathrm{Eq} /$ liter above resting levels, $30 \mathrm{~min}$ after infusion.

4. Comparison of the adipokinetic effectiveness of amphetamine and methamphetamine with the fat-mobilizing potency of epinephrine (Fig. 1, Table III)

The following indexes were used to quantitate the adipokinetic response: (a) peak plasma FFA,

TABLE III

Comparative Representation of the Different Indexes of Adipokinetic Effectiveness of Amphetamine and Methamphetamine Infusions in Relation to Effects of the Standard Epinephrine Infusion

\begin{tabular}{|c|c|c|c|c|c|c|c|c|c|c|c|c|c|}
\hline \multirow[b]{2}{*}{ Groups } & \multicolumn{7}{|c|}{$\triangle F F A$ data } & \multicolumn{6}{|c|}{ FFA kinetic data } \\
\hline & $\begin{array}{l}\text { Rising } \\
\text { slope }\end{array}$ & $\begin{array}{l}\text { Early } \\
\text { return- } \\
\text { ing } \\
\text { slope }\end{array}$ & $\begin{array}{l}\text { Late } \\
\text { return- } \\
\text { ing } \\
\text { slope }\end{array}$ & $\begin{array}{l}\text { Peak } \\
\text { rise }\end{array}$ & $\begin{array}{l}\text { Per } \\
\text { cent } \\
\text { v.s. } \\
\text { epi- } \\
\text { neph- } \\
\text { rine }\end{array}$ & $\begin{array}{c}+\Delta \text { FFA } \\
\text { area* }\end{array}$ & $\begin{array}{l}\text { Per } \\
\text { cent } \\
\text { v.s. } \\
\text { epi- } \\
\text { neph- } \\
\text { rine }\end{array}$ & $\Delta \mathrm{N}$ & $\begin{array}{c}\text { Per } \\
\text { cent } \\
\text { v.s. } \\
\text { epi- } \\
\text { neph- } \\
\text { rine }\end{array}$ & $\begin{array}{c}\mathrm{N} \\
\text { per cent } \\
\text { change }\end{array}$ & $\Delta \mathbf{R a}$ & $\begin{array}{c}\text { Per } \\
\text { cent } \\
\text { v.s. } \\
\text { epi- } \\
\text { neph- } \\
\text { rine }\end{array}$ & $\begin{array}{c}\text { Ra } \\
\text { per cent } \\
\text { change }\end{array}$ \\
\hline & & & & $\begin{array}{l}\mu E q / \\
\text { liter }\end{array}$ & & & & $\mu E q$ & & & $\begin{array}{c}\mu E q / \\
\min \end{array}$ & & \\
\hline $\begin{array}{l}\text { Amphetamine, } \\
15 \text { subjects }\end{array}$ & +7.17 & -5.70 & -1.17 & +326 & 55.3 & 17,205 & 83.7 & +1675 & 29.6 & +45.0 & +370 & 38.6 & +42.6 \\
\hline $\begin{array}{l}\text { Methamphetamine, } \\
6 \text { subjects }\end{array}$ & +5.42 & -4.13 & -0.22 & +244 & 41.5 & 15,925 & 77.5 & $+1440 \ddagger$ & $25.4 \ddagger$ & $+34.3 \ddagger$ & $+340 \ddagger$ & $35.5 \ddagger$ & $+32.9 \ddagger$ \\
\hline $\begin{array}{l}\text { Epinephrine, } \\
14 \text { subjects }\end{array}$ & +23.55 & -15.35 & -1.04 & +589 & 100.0 & 20,581 & 100.0 & +5660 & 100.0 & +128.5 & +958 & 100.0 & +83.9 \\
\hline
\end{tabular}

N : plasma FFA pool; Ra: plasma FFA production rate.

* In arbitrary units. + $\triangle$ FFA area is bounded by the temporal plot of the plasma FFA concentrations (from the beginning up to 90 min after the infusion of the compounds indicated) and a horizontal line drawn at the level of plasma FFA concentration obtainer at the beginning of the inf usion.

$\ddagger$ One subject. 

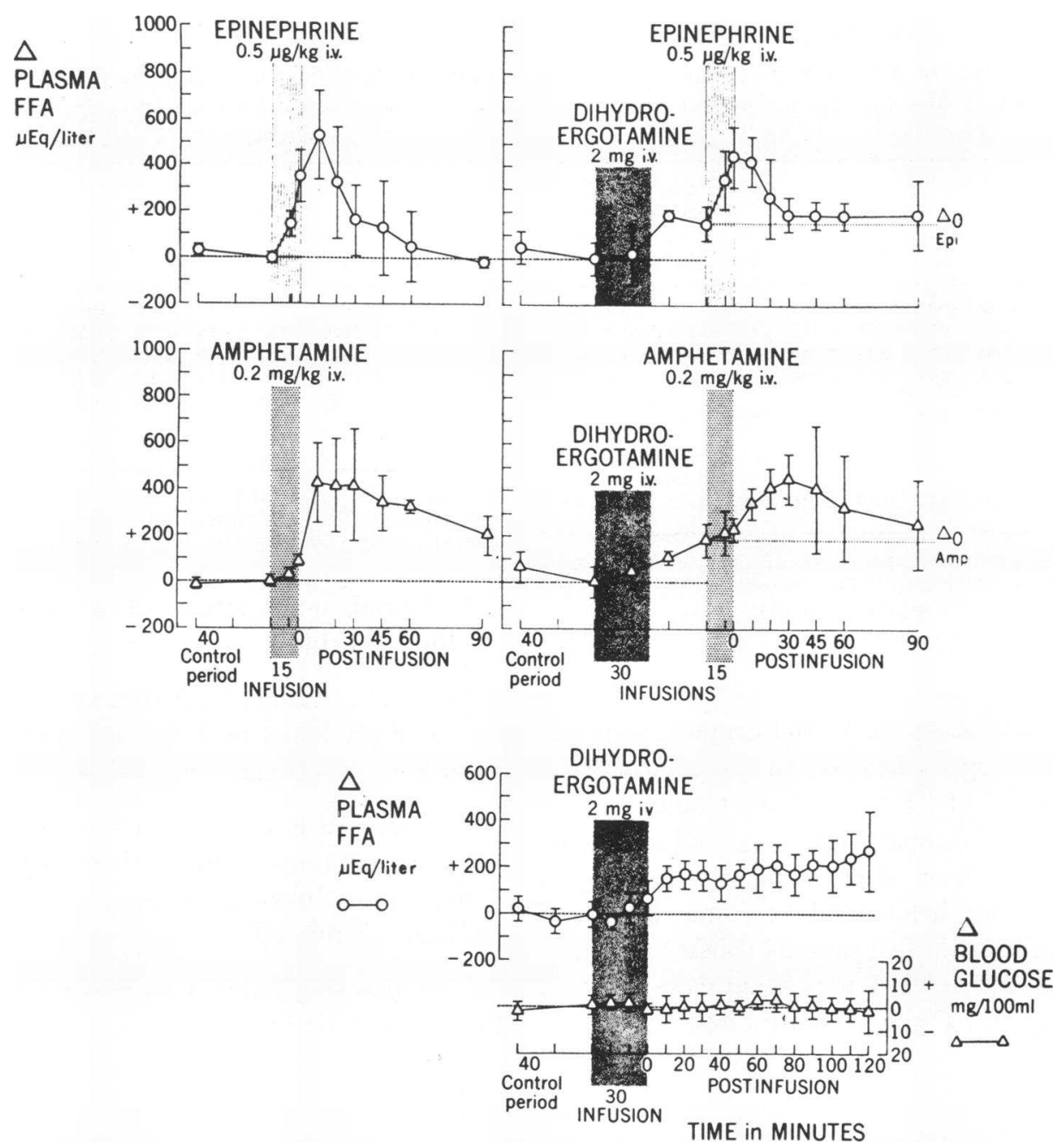

FIGURE 2 The effect of dihydroergotamine pretreatment on the fat-mobilizing action of intravenous epinephrine and amphetamine infusions (five subjects in each group) and the influence of intravenous dihydroergotamine alone on plasma FFA and blood glucose levels (in four subjects). The effects without pretreatment are included for comparison. Plasma FFA increased after dihydroergotamine (shown as $\Delta_{0}$ Epi and $\Delta_{0} A m p$ ). The subsequent changes were estimated in relation to these higher base lines, as dihydroergotamine alone caused a significant increase in plasma FFA concentration reaching a slightly rising plateau at 20 min, postinfusion.

(b) $+\Delta$ FFA area ${ }^{4}$ (see Fig. 1), (c) the absolute and per cent increment of plasma FFA production rate, and $(d)$ of plasma FFA pool size, measured after the administration of the compounds. The

4 Fig. 1 illustrates that the mean $\triangle F F A$ values become negative after $45 \mathrm{~min}$ after epinephrine whereas $+\triangle \mathrm{FFA}$ still persist at $90 \mathrm{~min}$ postamphetamine. As the comparisons were made in relation to a standard 90 min epinephrine procedure, the mean $+\triangle F F A$ area for amphetamine expresses: adipokinetic potency/an arbitrarily chosen unit of time (90 $\mathrm{min}$ ). more pronounced changes in $+\triangle \mathrm{FFA}$ area reflect the longer duration of action of amphetamine and methamphetamine in comparison with epinephrine. We believe that the latter data are more pertinent, from a physiological point of view, than the isolated consideration of peak effects.

5. Mechanism of adipokinetic action of amphetamine (Figs. 2 and 3)

The mode of action of amphetamine in mobilizing fat could be explained either by a direct action 
due to its aromatic amine structure or by an indirect effect via the release of endogenous catecholamines. In groups of four and five subjects two agents were used in an attempt to suppress epinephrine induced adipokinesis, dihydroergotamine $(2 \mathrm{mg} / 30 \mathrm{~m}$; i.v. $)$ and glucose $(250 \mathrm{mg} / \mathrm{kg}$ per $60 \mathrm{~min}$, i.v.). 'These substances were administered on separate o c c sions preceding amphetamine and epinephrine infus ${ }_{1}$ ns, respectively. Glucose administration suppresset both epinephrine and amphetamine induced adipokinesis. Intravenous dihydroergotamine led to a significant elevation of base line FFA, as was also observed with the specific $\alpha$ blocking agent, phenoxybenzamine (20). The fatmobilizing effect of both epinephrine and amphetamine were, however, suppressed to some extent (45 and $38 \%$, respectively, expressed as peak $\triangle F F A$ ) by the earlier administration of dihydroergotamine. These findings made the possibility of an adipokinetic action of amphetamine independent of its aromatic amine structure unlikely, as they indicated that a sympathomimetic amine was responsible for increased fat mobilization after amphetamine. The findings, however, did not indicate whether the responsible amine was amphetamine (direct action) or endogenous catecholamine released by the former compound (indirect action), since dihydroergotamine suppressed the effects of both epinephrine and amphetamine to nearly an equal degree.

In order to clarify the role of endogenous catecholamine release by amphetamine, we pretreated six subjects with large doses of parenteral reserpine. All experienced flushing of the skin, congestion of the nasal mucosa, and somnolence accompanied by a pronounced orthostatic hypotension. However, it was impossible to determine the degree of completeness of catecholamine depletion. When amphetamine was infused after $48 \mathrm{hr}$ of reserpine pretreatment there was a marked inhibi-

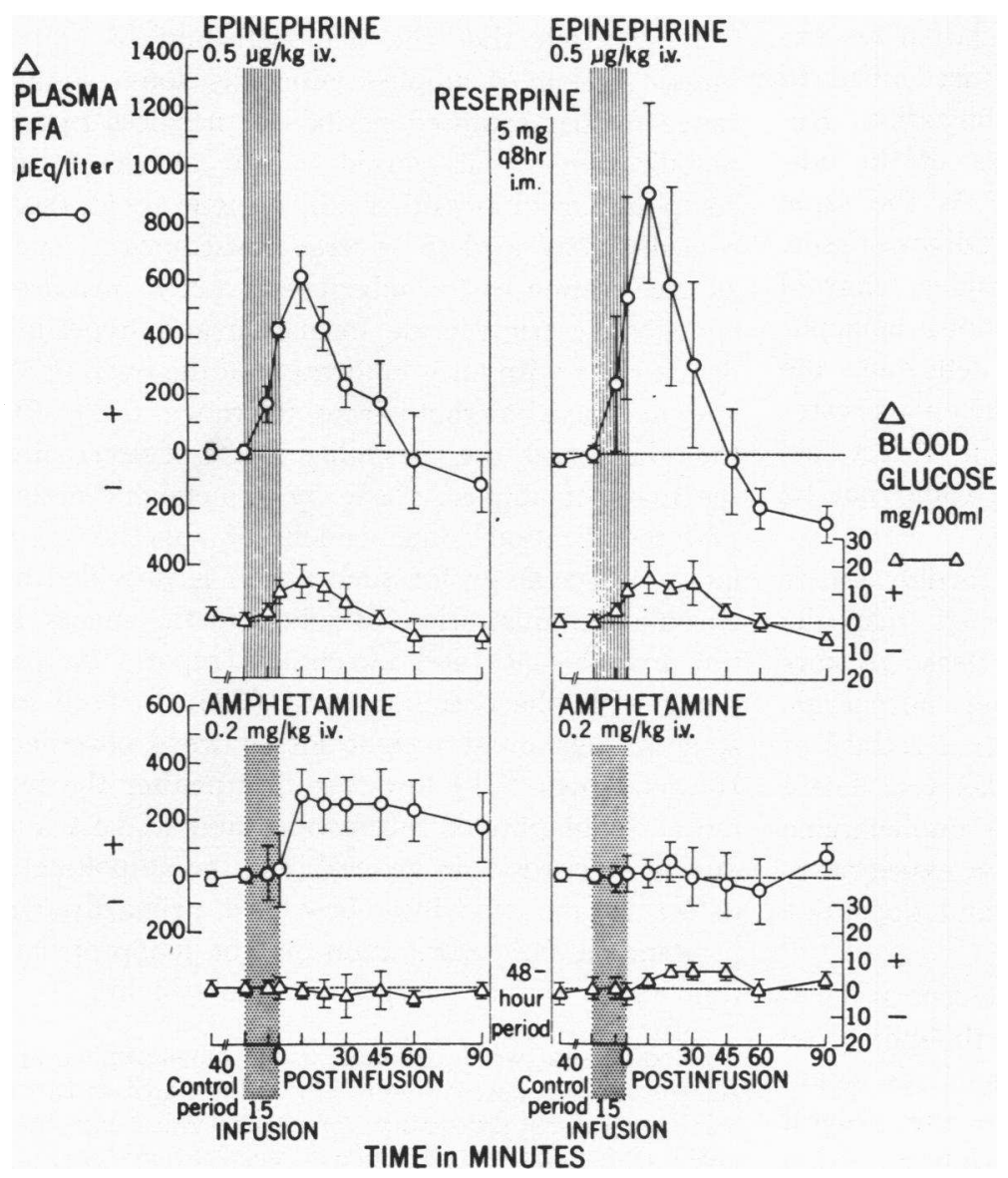

Figure 3 Modification of the effects of intravenous epinephrine and amphetamine infusions by prolonged reserpine administration (six subjects in each group). The changes $(\Delta) \pm \mathrm{SD}$ in plasma FFA and blood glucose levels are shown before and after a $48 \mathrm{hr}$ period of parenteral reserpine treatment. 
tion of the amphetamine induced adipokinesis ( $80 \%$, as suppression of peak FFA). Epinephrine given after reserpine pretreatment, on the other hand, was followed by an enhanced response (149\%, as peak FFA response) as judged by comparing the epinephrine effect without reserpine pretreatment in the same individuals. This part of the study was interpreted as evidence for the dependence of the amphetamine induced fat mobilization on endogenous catecholamine release.

\section{DISCUSSION}

In this study evidence was obtained that intravenous administration of amphetamine sulfate in man is followed within $30 \mathrm{~min}$ by an increase in the production rate of circulating FFA and also by an increase in the size of the plasma FFA pool and in FFA concentration. The rate of disappearance of FFA during the same period also increased, presumably due to mass action. This sequence was interpreted as indicating increased fat mobilization from the adipose tissue.

In the second part of the investigation we examined evidence for an indirect mechanism of action of amphetamine on fat mobilization. Reserpine pretreatment abolished most of the adipokinetic action of this substance. At the same time, the FFA-releasing capacity of adipose tissue, depleted of endogenous catecholamines, showed a substantial increase after exogenous epinephrine. In view of our inability to determine the completeness of depletion of endogenous catecholamines, the existence of a slight, direct fatmobilizing activity of amphetamine could not be excluded.

Pharmacological studies on the cardiovascular effects of amphetamine demonstrated that the mode of action is indirect, i.e., a release of norepinephrine from the postganglionic adrenergic nerves (21). The mechanism of actual release of stored norepinephrine is unknown as yet. There is evidence, however, that $(+)$ - amphetamine causes release of catecholamines from extragranular locations within noradrenaline and dopamine fibers (7).

The effects of amphetamine on the central nervous system, on the other hand, are thought to be elicited directly. Our studies of a metabolic action of amphetamine appear to confirm the general view of an indirect mechanism of peripheral action of this compound. The peak effect of amphetamine on the plasma FFA is consistently delayed by 20 min in comparison with epinephrine. The delay could possibly be explained by the time required for the interaction between amphetamine and endogenous catecholamines.

The relative adipokinetic potency of amphetamine, expressed as peak $\triangle F F A,+\Delta F F A$ area, and $\triangle F F A$ production rate, respectively, was found to be 55,84 , and $39 \%$ in comparison with the same effects of epinephrine. ${ }^{5}$

Dihydroergotamine, which has both $\alpha$ - and $\beta$-adrenergic receptor-blocking properties (23, 24), partially inhibited the fat-mobilizing action of both epinehprine and amphetamine. Interestingly, this compound also caused a significant increase in the base line FFA concentration, an effect also observed with the specific $\alpha$-blocking agent, phenoxybenzamine (20). The partial block of adipokinesis demonstrated with dihydroergotamine is attributed to the $\beta$-receptor-blocking effect of this compound.

It was felt that the demonstration of adipokinetic action of amphetamine has some significance in that repeated periods of needless hypermobilization of fat caused by the abuse of this compound or of any other adipokinetic agent, theoretically, may lead to adverse consequences, such as acceleration of thrombogenesis (25), increased endogenous triglyceride formation and hyperlipidemia (26) with fatty infiltration of the liver (27), and decreased carbohydrate tolerance (28). On the other hand, the possibility exists of decreasing the mass of adipose tissue by a metabolic action (fat mobilization) independent of appetite regulation. An analogy for such action is provided by chronic administration of adipokinetic agents in the animal (29) and by clinical reports on patients with pheochromocytoma (30). In both instances substantial weight losses were observed. It was shown (31) however that neither the humoral regulation of fat mobilization at rest and during starvation, in general, nor the adipokinetic defect in the starving obese are primarily dependent on the contribution and/or inappropriate function of the adrenergic nervous system.

\footnotetext{
5 These data were obtained using amphetamine and epinephrine in a dose ratio of $352: 1$ (calculated as base). The equipressor dose range of amphetamine has been given as $100-500: 1$, in relation to epinephrine (22).
} 


\section{ACKNOWLEDGMENTS}

The authors wish to express their gratitude to Drs. G. Hetenyi and G. A. Wrenshall, University of Toronto, for their generous help in designing the tracer studies and in the curve fittings and other calculations involving the use of computer; to Dr. T. Zsoter, University of Toronto, for his discussion and helpful advises concerning the pharmacology of the adrenergic nervous system; to Miss H. Wetzel and to Mr. W. Engelberg, Queen Mary Veterans Hospital, for their expert technical assistance, and to Mr. M. Kez, M.Sc., for the statistical evaluation of the data.

\section{REFERENCES}

1. Rudman, D., S. J. Brown, and M. F. Malkin. 1963. Adipokinetic actions of adrenocorticotropin, thyroidstimulating hormone, vasopressin, $\alpha$ - and $\beta$-melanocyte-stimulating hormones, fraction $\mathrm{H}$, epinephrine and norepinephrine in the rabbit, guinea pig, hamster, rat, pig and dog. Endocrinology. 72: 527.

2. Vaughan, M. 1960. Effect of hormones on phosphorylase activity in adipose tissue. J. Biol. Chem. 235: 3049.

3. Gordon, R. S., Jr., and A. Cherkes. 1956. Unesterified fatty acid in human blood plasma. J. clin. Invest. 35: 206.

4. Rudman, D., L. A. Garcia, S. J. Brown, M. F. Malkin, and W. Perl. 1964. Dose-response curves for the adipokinetic action of aromatic amines and adrenocorticotropin upon the isolated adipose tissue of the hamster. J. Lipid Res. 5: 28.

5. Piness, G., H. Miller, and G. A. Alles. 1930. Clinical observations on phenylaminoethanol sulphate. J. Am. Med. Assoc. 94: 790.

6. Alles, G. A. 1933. The comparative physiological actions of $\mathrm{dl}-\beta$-phenyl-isopropylamines. I. Pressor effect and toxicity. J. Pharmacol. Exptl. Therap. 47: 339.

7. Carlsson, A., K. Fuxe, B. Hamberger, and M. Lindqvist. 1966. Biochemical and histochemical studies on the effects of imipramine-like drugs and $(+)$-amphetamine on central and peripheral catecholamine neurons. Acta Physiol. Scand. 67: 481

8. Innes, I. R. 1963. Action of dexamphetamine on 5hydroxytryptamine receptors. Brit. J. Pharmacol. 21 : 427.

9. Kessler, J. I., M. Demeny, and H. Sobotka. 1967. Rates of tissue uptake of palmitic acid-1- ${ }^{14} \mathrm{C}$ complexed with albumin by two different procedures. J. Lipid Res. 8: 185 .

10. Adlersberg, D., E. T. Bossak, I. H. Sher, and H. Sobotka. 1955. Electrophoresis and monomolecular layer studies with serum lipoproteins. Clin. Chem. 1: 18.

11. Hetenyi, G., Jr., A. M. Rappaport, and G. A. Wrenshall. 1961. The validity of rates of glucose appearance in the dog calculated by the method of successive tracer injections. I. Effects of surgical hepatectomy, evisceration, and order of tracer injection. Can. J. Biochem. Physiol. 39: 225.

12. Wrenshall, G. A., and G. Hetenyi, Jr. 1963. Tests of the validity of tracer-calculated amounts and transfer rates of substances in the blood plasma of living animal systems. Ann. N. Y. Acad. Sci. 108: 259.

13. Wrenshall, G. A., and G. Hetenyi, Jr. 1959. Successive measured injections of tracer as a method for determining characteristics of accumulation and turnover in higher animals with access limited to blood: Tests in hydrodynamic systems and initial observations on insulin action in dogs. Metabolism. 8: 531.

14. Bragdon, J. H. 1960. Extraction of lipids from serum. A. General considerations. B. Method for extraction of serum lipids. In Lipids and the Steroid Hormones in Clinical Medicine; Proceedings of an Applied Seminar. F. W. Sunderman and F. W. Sunderman, Jr., editors. J. B. Lippincott Co., Philadelphia. 2: 6-8.

15. Van Handel, E. 1961. Suggested modifications of the micro determination of triglycerides. Clin. Chen. 7: 249.

16. Dole, V. P. 1956. A relation between non-esterified fatty acids in plasma and the metabolism of glucose. J. Clin. Invest. 35: 150.

17. Trout, D. L., E. H. Estes, Jr., and S. J. Friedberg. 1960. Titration of free fatty acids of plasma; a study of current methods and a new modification. J. Lipid Res. 1: 199.

18. Hoffman, W. S. 1937. A rapid photoelectric method for the determination of glucose in blood and urine. J. Biol. Chem. 120: 51.

19. Friedberg, S. J., W. R. Harlan, Jr., D. L. Trout, and E. H. Estes, Jr. 1960. The effect of exercise on the concentration and turnover of plasma nonesterified fatty acids. J. Clin. Invest. 39: 215.

20. Pinter, E. J., C. J. Pattee, G. Peterfy, and J. M. Cleghorn. 1967. Metabolic effects of autonomic blockade. Lancet. 2: 101.

21. Innes, I. R., and M. Nickerson. 1965. Drugs acting on postganglionic adrenergic nerve endings and structures innervated by them (sympathomimetic drugs). In The Pharmacological Basis of Therapeutics. L. S. Goodman and A. Gilman, editors. The Macmillan Company, New York. 3rd edition. 24: 479.

22. Gunn, J. A., M. R. Gurd, and I. Sachs. 1939. Action of some amines related to adrenaline: methoxyphcuylisopropylamines. J. Physiol. $95: 485$.

23. Goodman, H. M., and E. Knobil. 1959. Effect of adrenergic blocking agents on fatty acid mobilization during fasting. Proc. Soc. Exptl. Biol. Med. 102: 493.

24. Levy, B., and R. P. Ahlquist. 1961. An analysis of adrenergic blocking activity. J. Pharmacol. Exptl. Therap. 133: 202.

25. Connor, W. E., J. C. Hoak, and E. D. Warner. 1963. Massive thrombosis produced by fatty acid infusion. J. Clin. Invest. 42: 860.

26. Nestel, P. J. 1964. Plasma triglyceride concentration and plasma free fatty acid changes in response to norepinephrine in man. J. Clin. Invest. 43: 77. 
27. Carlson, L. A., S. O. Liljedahl, and C. Wirsen. 1965. Blood and tissue changes in the dog during and after excessive free fatty acid mobilization. A biochemical and morphological study. Acta Med. Scand. 178: 81.

28. Schalch, D. S., and D. M. Kipnis. 1965. Abnormalities in carbohydrate tolerance associated with elevated plasma nonesterified fatty acids. J. Clin. Invest. 44: 2010.

29. Kekwick, A., and G. L. S. Pawan. 1963. An experimental approach in the mechanism of weight loss. II. A comparison of effects of thyroxine, fat-mobilizing substance (FMS) and food deprivation in achieving weight loss in mice. Metabolism. 12: 222.

30. Gifford, R. W., Jr., W. F. Kvale, F. T. Maher, G. M. Roth, and J. T. Priestley. 1964. Clinical features, diagnosis and treatment of pheochromocytoma: A review of 76 cases. May'o Clin. Proc. 39: 281.

31. Pinter, E. J., and C. J. Pattee. Some data on the metabolic function of the adrenergic nervous system in the obese and during starvation. J. Clin. Endocrinol. Metab. In press. 